HortSCIENCE 26(10):1303-1305. 1991.

\title{
The Near Infrared Determination of Moisture in Whole Dates
}

\author{
Gerald G. Dull', Richard G. Leffler ${ }^{2}$, Gerald S. Birth ${ }^{3}$, \\ Arthur Zaltzman', and Ze'ev Schmilovitch ${ }^{4}$ \\ Richard B. Russell Agricultural Research Center, Agricultural Research \\ Service, U.S. Department of Agriculture, P. O. Box 5677 Athens, \\ GA 30613
}

Additional index words. Phoenix dactylifera, grades, standards, quality

\begin{abstract}
Whole dates (Phoenix dactylifera L.) were analyzed for moisture content using near infrared spectrophotometry in a direct transmittance geometry. In the calibration experiment using 72 samples, the correlation coefficient was 0.977 and the standard error of calibration (SEC) was $0.89 \%$. When the calibration equation was used to predict the moisture in another set of 72 date samples, the standard error of performance (SEP) was $1.5 \%$. When the method was used to sort these 72 dates into four industry-standard grades, $74 \%$ were correctly graded and $15 \%$ missed the grade by $<1$ SEC.
\end{abstract}

The U.S. Dept. of Agriculture standards for grades of dates (U.S. Dept. Agriculture, 1955) are based on color, uniformity of size, absence of defects, and character. Character is based on three attributes: development, maturity, and moisture. Development and maturity are subjective judgments that are interrelated with moisture, an objective measurement. In practice, all grading is accomplished manually and is subjective. Moisture measurement, when performed, can be considered a quality control procedure to evaluate the adequacy of the sorting procedure. The U.S. date industry uses its own standards (Chesson et al., 1979), which have moisture content as a principal criterion, with grades specified as follows: naturals, $>23 \%$ moisture; waxy, $20 \%$ to $23 \%$ moisture; No. 1 dry, $15 \%$ to $19 \%$ moisture; and No. 2 dry, $<15 \%$ moisture. The conventional method

Received for publication 3 Dec. 1990. The cooperation of the Dole Dried Fruit and Nut Co. is gratefully acknowledged, as is the statistical assistance of Ruel Wilson and the technical assistance of Alice Wilcher. This work was partially supported by funds made available through grant no. 1173-86 from BARD (United States-Israel Binational Agricultural Research and Development Fund). The cost of publishing this paper was defrayed in part by the payment of page charges. Under postal regulations, this paper therefore must be hereby marked advertisement solely to indicate this fact.

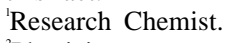

${ }^{2}$ Physicist.

${ }^{3}$ Agricultural Engineer, retired. Present address: 3701 Bryant Ave. S.. Minneapolis, MN 55409. ${ }^{4}$ Agricultural Engineer, Agricultural Engineering Inst., A. R. O., Bet Dagan, Israel. for the determination of moisture in dates is drying in a vacuum oven at $70 \mathrm{C}$ for $20 \mathrm{~h}$ (Schiller and Maier, 1958). A rapid and reliable determination of moisture at any stage of processing or marketing of dates is a distinct need of the U.S. date industry (F. Moshbar, personal communication). Dates were selected for this study because they are a product with an intermediate moisture range (10\% to $30 \%$ moisture) that has not been investigated by near infrared (NIR) radiation and because objective moisture content standards exist for dates. An automated method for moisture determination in dates would likely have application to other dried fruits.

When NIR radiation falls on a sample, such as a date, some enters the sample, undergoes multiple scattering, and exits the sample, usually close to the point of entrance. Such radiation is said to be diffusely reflected. A much smaller amount of radiation will be scattered in such a manner that it exits on the far side of the sample. This radiation is said to be diffusely transmitted. Radiation that is subjected to multiple scattering within the sample also is absorbed at various wavelengths characteristic of the chemical composition of the sample. When diffusely reflected or transmitted radiation is detected as a function of wavelength, absorption spectra are generated. In many cases, the amount of radiation absorbed at a specific wavelength can be related to the amount of a constituent and, thus, could become a means of quantitating that constituent. NIR diffuse reflectance has found wide application for the quantitation of protein, lipids, and moisture in dry samples (Polesello and Giangiacomo, 1983). With the recent ad- 


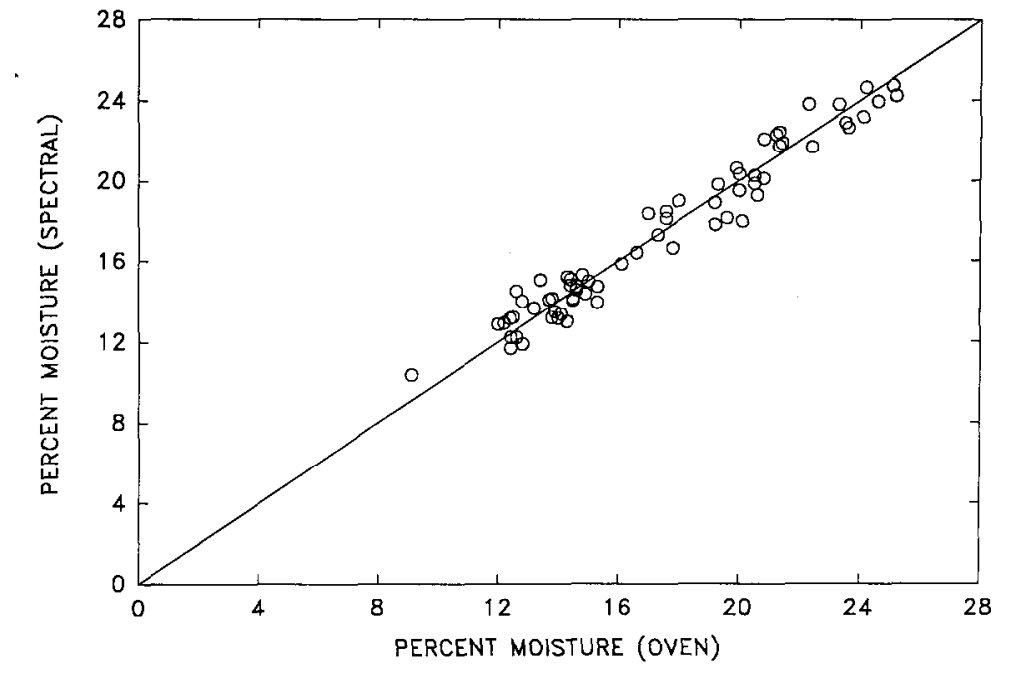

Fig. 1. Spectral moisture values vs. oven moisture values for dates in calibration sample set.

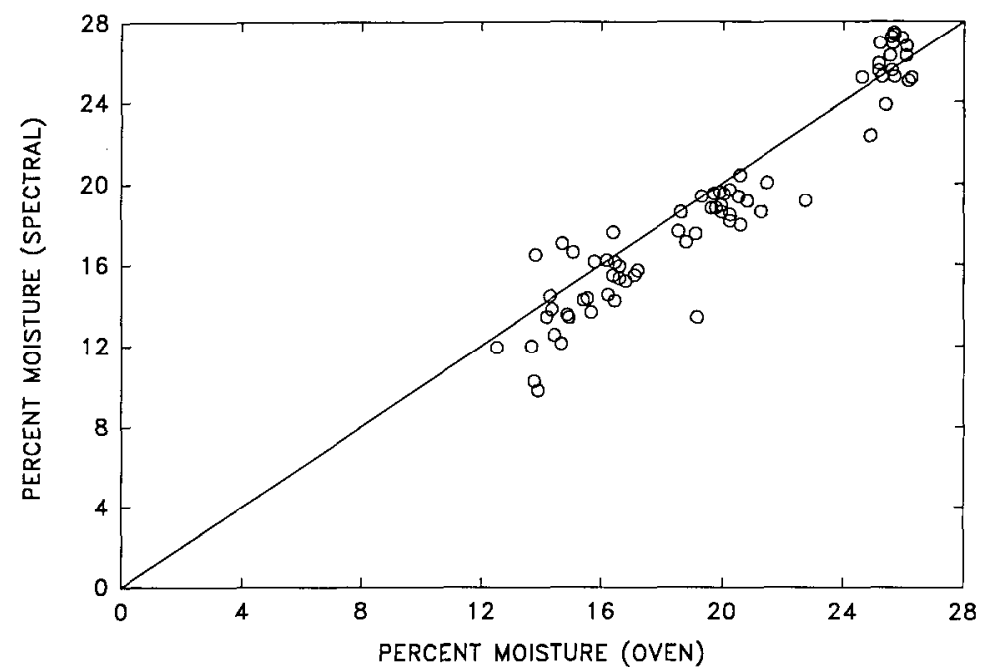

Fig. 2. Spectral moisture values vs. oven moisture values for dates in validation sample set.

vances in this technology, use of diffusely transmitted NIR radiation from intact fruits and vegetables has made it possible to gain information about the internal composition of those products (Birth et al., 1985; Dull et al., 1989). A NIR-based method to determine moisture content of dates could facilitate the automation of date grading. This paper reports the application of direct transmittance NIR spectrophotometry for nondestructive determination of moisture in whole dates.

The samples of 'Deglet Noor' dates (Dole Dried Fruit and Nut Co., Indio, Calif.) covered the four moisture ranges of the industry standards, and individual dates in each sample varied in moisture content within the single range, thus providing dates within a wide range of moisture contents. The dates in each of these groups were packaged in units of 10 dates/package to minimize the effect of moisture equilibration in larger lots during storage. This procedure provided samples of as wide a moisture range as possible during the experiment. To measure date moisture content under our conditions, it was neces- sary to use a modification (vacuum oven, 48 $\mathrm{h}, 70 \mathrm{C}$ ) of the conventional procedure (Schiller and Maier, 1958), since a 24-h drying time was inadequate to obtain a stable dry weight. The moisture content of samples ranged from $9 \%$ to $26 \%$. Two sets of samples were prepared, each of which contained 72 dates that were equally distributed over the four moisture ranges (see Figs. 1 and 2). One set was used as the calibration set and the other as the validation set.

A biological spectrophotometer, the Biospect, designed to accommodate a wide range of sample shapes and sizes, was used (Birth and Zachariah, 1973). The incident beam from the spectrophotometer passed through the date sample, where the radiation was extensively scattered (diffused) and some of the exiting radiation was picked up by a silicon detector placed on the opposite side of the date from the incident beam. In this manner, radiation that has passed through the entire sample can be used rather than reflected radiation, which would provide information mainly about the surface of the sample. This direct transmittance geometry was selected because dif- fusely transmitted radiation is representative of the whole date and it could be readily adapted to an automated sorting process. The wavelength region scanned was 800 to 1050 $\mathrm{nm}$. A 16-mm-thick metal disk, with a trough machined to accommodate a date, served as the sample holder. The trough had a $3 \times$ 20 -mm slot in the bottom to enable transmitted radiation to exit the sample and reach the detector. Before scanning the dates, a reference data set was taken with a neutraldensity filter in the incident beam. The ratio of the date spectral data to the reference data at each wavelength was computed to produce a transmittance (T) spectrum, which was then converted into an optical-density-like spectrum by taking the logarithm of in. The spectrum for each date consisted of 500 data points.

Our experience (Birth et al., 1985; Dull et al., 1989) has shown that the best prediction results were obtained with $\log (1 / \mathrm{T})$ spectra that were modified by taking a second derivative with respect to wavelength. This method reduces spectral variations due to radiation scattering and sample size. The spectral and moisture data for all dates in a sample set were processed with a commercial linear regression software package (NIR Systems, Silver Spring, Md.). The program calculated ratios of second derivatives for all combinations of wavelengths; these ratios were regressed on the moisture data. The parameters used in these calculations include the number of samples (n), numerator (num) and denominator (den) wavelengths (WL), segment (number of WL used in smoothing), and gap (WL intervals in second-derivative calculation). The procedure identified the two wavelengths such that the ratio of their second derivatives gave the highest correlation coefficient when spectral data were regressed on moisture data. The analysis also gave the values of the constants in the following regression equation: $\%$ moisture $=$ $\mathrm{K}_{0}+\mathrm{K}_{1} \mathrm{X}$, where $\mathrm{K}_{0}$ is the regression equation intercept, $\mathrm{K}_{1}$ is the regression equation slope, and $\mathrm{X}$ is the ratio of two second derivatives.

A more detailed discussion of the dataprocessing method can be found in Birth et al. (1985). Calibration is the process of combining known moisture data with spectral data to develop a prediction equation by means of regression analysis. This regression equation was used as the calibration equation to predict the percentage of moisture in the validation sample set. The standard error of calibration (SEC) is a measure of the quality of the correlation between the spectral and chemical data for the calibration data set.

$\mathrm{SEC}=\left[\frac{\sum_{i=1}^{\mathrm{n}}\left(\mathrm{NIR} \text { value }_{i}-\text { Lab value }_{i}\right)^{2}}{n-2}\right]$

The standard error of performance (SEP) measures the accuracy of the calibration equation for prediction of moisture in other date samples. The SEP is derived from an 
equation similar to that used for the calibration of the SEC.

One set of 72 date samples was used as the calibration set and was scanned to obtain the spectral data. The moisture data obtained by the drying method ranged from $9.1 \%$ to $25.2 \%$. In the initial regression analysis, five of the samples were outliers (error $>2 x$ the SEC) when the regression equation was used to predict the moisture values from the spectral data. Examination of the raw spectral data revealed aberrations from expected curve shapes for these five samples. Inadequate seating of the sample in the sample holder could produce such aberrations. When the regression analysis was repeated after deleting the five samples from the data set, the correlation coefficient (r-) was 0.977 with a SEC of $0.89 \%$. The data-processing parameters for the calibration equation are: $n, 67$; segment, 21; num gap, 9; num WL, $925 \mathrm{~nm}$; den gap, 9; den WL, 955 run. Figure 1 shows the spectrally predicted moisture values vs. the drying method values for the calibration sample set. The calibration equation was then used to predict the moisture values in the validation sample set. The SEP for this sample set was $1.5 \%$. Figure 2 shows the spectrally predicted vs. drying-method moisture values for the validation sample set. The vigor of the correlation is supported by the sample size $(n=72)$ and the even distribution of the samples over the entire moisture range.

The results from the validation sample set can be used to assess the accuracy of the NIR method for sorting dates into the four industry-standard grades. Out of 72 dates, 53 (74\%) were correctly graded. No sample was off by more than one grade. If an error of one SEC $(0.89 \%)$ was considered acceptable, 64 dates $(89 \%)$ were adequately graded. For the calibration equation to perform ideally for prediction, the SEP should about equal the SEC. For the validation sample set, the SEP was almost twice the SEC. Of the seven samples whose predicted moisture values differed from the oven method by $>2.5 \%$, six had predicted values that were too low. This deviation is consistent with the existence of a small radiation leak around the sample during measurement. It should be possible to eliminate the light leak by redesigning the sample holder.

We conclude that a NIR-spectrophotometer-based method can nondestructively grade dates on the basis of moisture content. If the method is implemented with a rapidscanning spectrophotometer, fast date sorting could be achieved.

\section{Literature Cited}

Birth, G. S., G.G. Dull, W.T. Renfroe, and S.J. Kays. 1985. Nondestructive spectrophotometric determination of dry matter in onions. J. Amer. Soc. Hort. Sci. 110(2):297-303.

Birth, G.S. and G.L. Zachariah. 1973. Spectrophotometer for biological applications. Trans. Amer. Soc. Agr. Eng. 16(2):371-372.

Chesson, J. H., P.F. Burkner, and R.M. Perlins. 1979. An experimental vacuum separator for dates. Trans. Amer. Soc. Agr. Eng. 22(1):1620.

Dull, G. G., G.S. Birth, and R.G. Leffler. 1989.
Use of near infrared analysis for the nondestructive measurement of dry matter in potatoes. Amer. Potato J. 66:215-225.

Polesello, A. and R. Giangiacomo. 1983. Application of NIR spectrophotometry to the nondestructive analysis of foods: A review of experimental results. CRC Crit. Rev. Food Sci. Nutr. 18:203-230.
Schiller, F.H. and V.P. Maier. 1958. Evaluation of some physical methods for determining the moisture content of dates. Date Grower's Inst. Rpt. 35:19-22.

U.S. Department of Agriculture. 1955. Standards for grades of dates. U.S. Dept. of Agr. Mktg. Serv., Fruit and Vegetable Div., Processed Products Branch, Washington, D.C. 